\title{
Recurrent erythema multiforme with arthritis - A rare association
}

\author{
Yasmeen Jabeen Bhat', Sumaya Zeerak', Asif Nazir Baba², Iffat Hassan', Roohi Wani² \\ ${ }^{1}$ Departments of Dermatology, STD \& Leprosy, Government Medical College, University of Kashmir, Srinagar, India, \\ ${ }^{2}$ Departments of Orthopedics, Government Medical College, University of Kashmir, Srinagar, India, ${ }^{3}$ Departments of \\ Pathology, Government Medical College, University of Kashmir, Srinagar, India
}

Corresponding author: Dr. Yasmeen Jabeen Bhat, E-mail: yasmeenasif76@gmail.com

\begin{abstract}
Erythema multiforme (EM) is an acute, immune-mediated, self-limiting mucocutaneous condition characterized by distinctive target lesions. The etiology is diverse and numerous diseases have been associated with EM. However, arthritis has been rarely reported with it. We report a rare association between EM, localized mainly over the joints, and polyarthritis in a male patient, who responded successfully to oral acyclovir.
\end{abstract}

Key words: Erythema multiforme; Recurrent; Arthritis

What's Known: Erythema multiforme minor is rarely associated with arthritis.

\section{INTRODUCTION}

Erythema multiforme (EM) is an acute, immunemediated, self-limited mucocutaneous condition characterized by distinctive target lesions with concentric colour variations [1-3]. It is believed to be the result of a type four hypersensitivity reaction, occuring as a consequence to an underlying trigger. It can occur as a single episode or the lesions can recur in the form of multiple episodes, with a highly variable interval between these episodes [2]. In those patients where EM has a remitting -relapsing course, over months or years, the condition is known as recurrent erythema multiforme [1]. This causes significant distress to the patient, necessitating a thorough search for the underlying trigger. Erythema multiforme can have association with a variety of diseases [4]. Here we report a rare association between EM and polyarthritis in a male patient.

\section{CASE REPORT}

A 25 years old male patient, reported to our dermatology OPD with the complaints of red, raised lesions over the joints of both hands, feet, elbows, knees and ankles with pain and swelling of the small joints of hand. These lesions had been appearing for the last 3 years, with a remitting and relapsing course. As per the patient, the lesions had first appeared over the joints of his hands nearly 3 years ago and were associated with pain and swelling of these joints. The eruption was preceeded by fever and the patient had associated constitutional symptoms also. The episode lasted for a few days at that time. This was followed by a period of remission, lasting for a few weeks. Soon the patient developed fresh lesions over his hand joints again, followed by the joints of feet, elbows and knees. These lesions had the same course as above but the extent was widespread with severe pain, swelling and limited movements of the affected joints of hands, feet, elbows and knees. Multiple such episodes following the same course, occurred 
over the subsequent three years, with periods of remission in between. An interesting finding was the exacerbation of lesions during cold weather with a history of recurrent oral herpes often preceeding the cutaneous eruption. There was no significant drug intake prior to the appearance of lesions. Moreover the joint involvement had started with the cutaneous eruption and was not present before 3 years. There was no history of morning stiffness or any other significant complaint in the history.

On examination, the general physical examination was found to be unremarkable. The cutaneous examination revealed multiple erythematous to violaceous crusted papules, erosions, pustules and atypical target lesions distributed over the arms, forearms (extensor surfaces), hands (including dorsa of both hands, dorsal and palmar surfaces of fingers especially over metacarpophalangeal, proximal and distal interphalangeal joints), knees, lower legs, dorsa of both feet (predominantly over the metatarsophalangeal and interphalangeal joints of feet) (Figs 1 - 3). The interphalangeal joints of

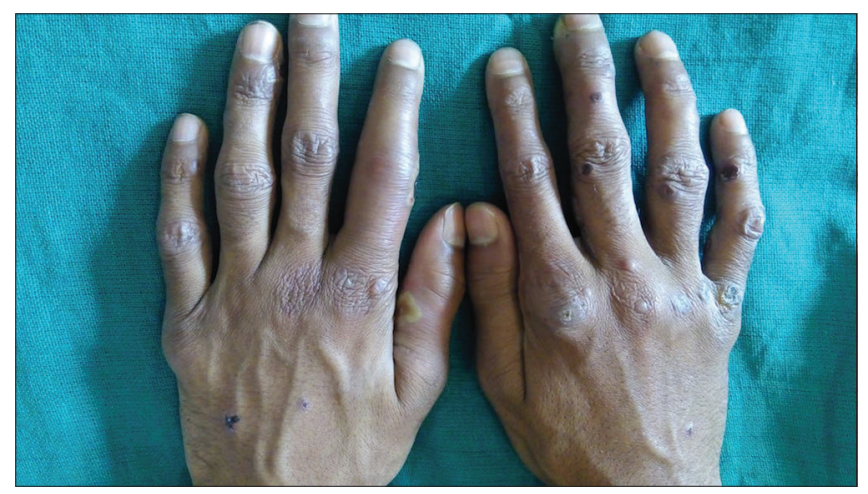

Figure 1: Atypical target lesions on the hands involving mainly the joints.

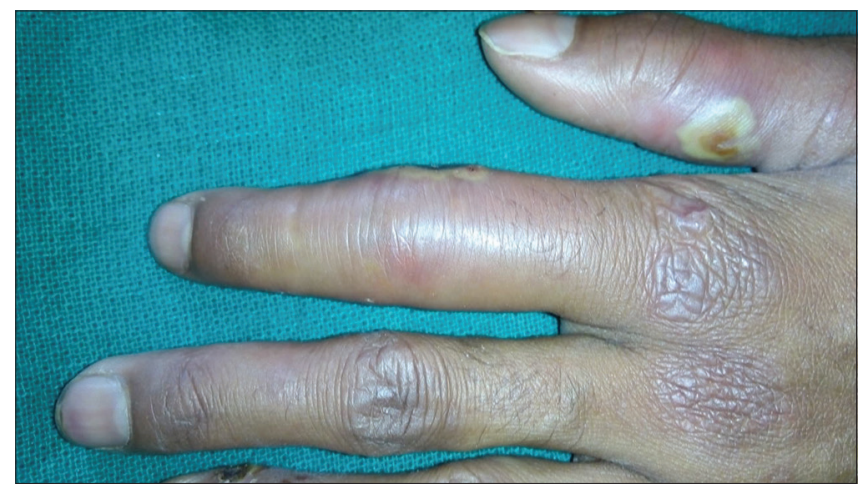

Figure 2: Inflammed left proximal interphalingeal joint of index finger and thumb. left thumb and index finger along with the joints of knee, elbow, feet were erythematous and swollen, tender, with reduced range of movements. The surface temperature was also raised. No mucosal lesion was present.

The routine haematological investigations were within normal limits including ASO titre and C- reactive protein. Serum anti- nuclear antibody, rheumatoid factor and anti- CCP (anti- citrullinated peptide) levels were also done, which were all negative. Serum IgG and IgM anti-HSV 1 were positive. X-rays of the affected joints revealed mild soft tissue edema. A histopathological examination of the cutaneous lesions was performed and the features were consistent with the diagnosis of erythema multiforme (Fig. 4).

Following this, the patient was put on oral acyclovir $400 \mathrm{mg}$ tid. The cutaneous lesions as well as the arthritis resolved within a period of two weeks (Fig. 5). The patient was put on suppressive therapy for herpes simplex for six months and was free of lesions for this period and next six months.

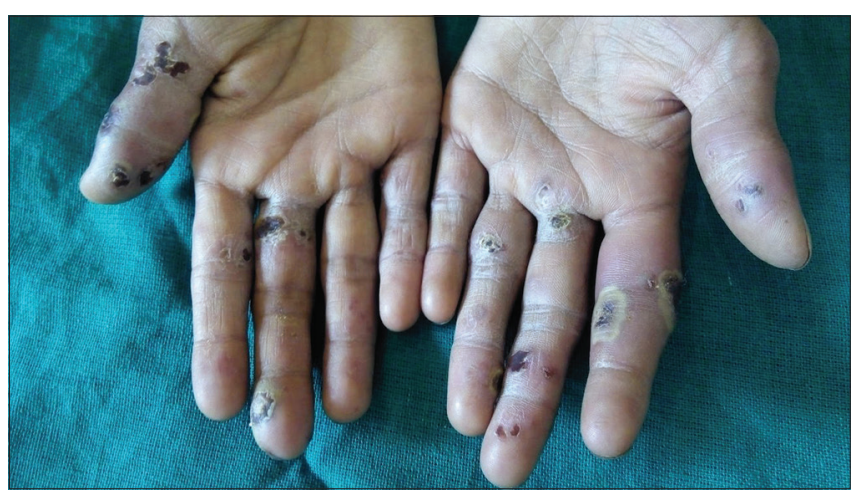

Figure 3: Target lesions on palmar aspect of hands.

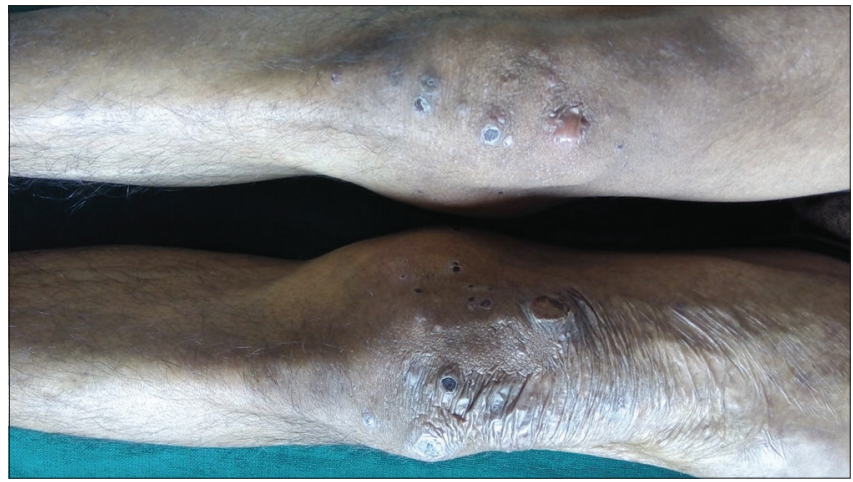

Figure 4: Involvement of knee joints. 


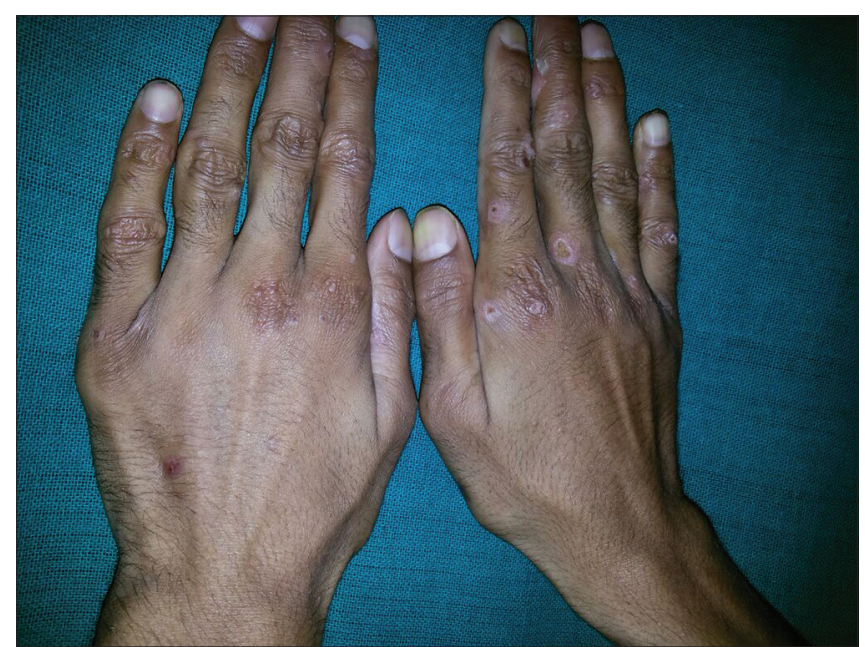

Figure 5: Resolution of lesions and joint swelling after two weeks of acyclovir intake.

\section{DISCUSSION}

First described by Ferdinand von Hebra in 1866, erythema multiforme is an acute, mucocutaneous disorder considered to be a hypersensitivity reaction associated with certain infections and medications $[2,5]$. It is characterized by acrally distributed, distinct targetoid lesions with concentric color variation, sometimes accompanied by oral, genital, or ocular mucosal erosions or a combination of these [6]. The etiology is diverse with a huge list of causative agents reported in literature. The main causes include infections, medication use, malignancy, autoimmune disease, radiation, immunization, and menstruation [2]. In addition, numerous other agents have been incriminated and numerous disease associations reported.

Viral infection, especially by herpes simplex virus is believed to be one of the most common etiological agents for EM with studies reporting a 70\% causality of EM due to this virus alone $[7,8]$. A distinct term has been coined for such cases where the virus is responsible for recurrent episodes of EM, namely herpes- associated EM (HAEM) [9].

Even though numerous diseases, both immunological and non- immunological have been associated with EM, arthritis has been rarely associated with it. Contrary to the arthralgias seen in most of the EM patients, our patient had features of arthritis with no evidence of any connective tissue disorder. Although herpes group of viruses is most commonly attributed etiological agent of connective tissue disorders like SLE and RA, but studies show no statistical significance of
HSV 1 and 2 serology in these patients and the healthy controls $[10,11]$.

In our patient, the remitting and relapsing course of the disease, history of orolabial herpes often preceding the eruption and constitutional symptoms, all favoured the viral etiology of erythema multiforme. However the preponderance of lesions over the joints of upper and lower limbs with associated features of arthritis in the hand joints was a unique association.

Recurrent EM has been treated successfully with a number of drugs, including oral antiviral drugs [12]. A similar case was reported wherein the recurrent cutaneous lesions of erythema multiforme and polyarthritis responded to oral acyclovir [13]. The resolution of the cutaneous lesions as well as the arthritis with anti-viral drugs could be due to the common pathogenesis of the two conditions which would require further studies.

What's new: Recurrent erythema multiforme minor was associated with polyarthritis repeatedly in the same joints, that too responded to oral antiviral therapy.

\section{Consent}

The examination of the patient was conducted according to the Declaration of Helsinki principles.

\section{REFERENCES}

1. Schofield JK, Tatnall FM, and Leigh IM. Recurrent erythema multiforme: clinical features and treatment in a large series of patients. Br J Dermatol. 1993;128:542-5.

2. Huff JO, Weston WL, and Tonnesen MG. Erythema multiforme: a critical review of characteristics, diagnostic criteria, and causes. J Am Acad Dermatol. 1983;8:763-75.

3. Howland WW, Golitz LE, Weston WL, Huff JC. Erythema multiforme: clinical, histopathologic, and immunologic study. J Am Acad Dermatol. 1984;10:438-46.

4. Bhat YR, Varma C, Bhatt S, Balachandran C. Rowell syndrome. Indian Dermatol Online J. 2014;5:33-5.

5. Williams PM, Conklin RJ. Erythema multiforme: A review and contrast from Stevens-Johnson syndrome/toxic epidermal necrolysis. Dent Clin North Am. 2005;49:67-76.

6. Assier H, Bastuji-Garin S, Revuz J, Roujeau JC. Erythema multiforme with mucous membrane involvement and StevensJohnson syndrome are clinically different disorders with distinct causes. Arch Dermatol. 1995;131:539-43.

7. Kokuba H, Imafuku S, Huang S, Aurelian L, Burnett JW. Erythema multiforme lesions are associated with expression of a herpes simplex virus (HSV) gene and qualitative alterations in the HSV-specific T-cell response. Br J Dermatol. 1998;138:952-64.

8. Sun Y, Chan RK, Tan SH, Ng PP. Detection and genotyping of human herpes simplex viruses in cutaneous lesions of erythema multiforme by nested PCR. J Med Virol. 2003;71:423-8.

9. Weston LW. Herpes-associated erythema multiforme. J Investig 


\section{www.odermatol.com}

Dermatol. 2005;124:15-6.

10. Bhobe MR, Tambe S, Jindal S, Jerajani HR. Rowell's Syndrome to ds-DNA Negative Lupus Nephritis: A Yet Unreported Progression. Indian J Dermatol. 2015;60:215.

11. Us T, Cetin E, Kaşifoğlu N, Kaşifoğlu T, Akgün Y. Investigation of Epstein-Barr virus and herpes simplex virus markers by serological and molecular methods in patients with rheumatoid arthritis and systemic lupus erythematosus]. Mikrobiyol Bul. 2011;45:677-83.

12. Tatnall FM, Schofield JK, and Leigh IM. A double-blind, placebocontrolled trial of continuous acyclovir therapy in recurrent erythema multiforme. Br J Dermatol. 1995;132: 267-70.

13. Molnar I, Matulis M. Arthritis associated with recurrent erythema multiforme responding to oral acyclovir. Clin Rheumatol. 2002;21:415-7.

Copyright by Yasmeen Jabeen Bhat, et al. This is an open access article distributed under the terms of the Creative Commons Attribution License, which permits unrestricted use, distribution, and reproduction in any

medium, provided the original author and source are credited.

Source of Support: Nil, Conflict of Interest: None declared. 